\title{
Brief Report: Character Strengths in Adults with Autism Spectrum Disorder Without Intellectual Impairment
}

\author{
Kirchner, Jennifer ; Ruch, Willibald ; Dziobek, Isabel
}

\begin{abstract}
In the current study, we assessed character strengths in individuals with autism spectrum disorder (ASD, $\mathrm{n}=32)$ and neurotypical controls $(\mathrm{n}=32)$ using the Values in Action Inventory (VIAIS, Peterson and Seligman 2004) and explored associations with levels of satisfaction with life (SWL). The most frequently endorsed signature strengths (i.e., five top-ranked strengths within an individual's strength ranking) were emotional (humour, love) and interpersonal strengths (kindness, fairness) in the control group, the most frequently endorsed signature strengths in the ASD group were intellectual strengths (open-mindedness, creativity, love of learning). Interpersonal and emotional strengths had, however, the highest positive associations with SWL in the ASD group.
\end{abstract}

DOI: https://doi.org/10.1007/s10803-016-2865-7

Posted at the Zurich Open Repository and Archive, University of Zurich

ZORA URL: https://doi.org/10.5167/uzh-147255

Journal Article

Accepted Version

Originally published at:

Kirchner, Jennifer; Ruch, Willibald; Dziobek, Isabel (2016). Brief Report: Character Strengths in Adults with Autism Spectrum Disorder Without Intellectual Impairment. Journal of Autism and Developmental Disorders, 46(10):3330-3337.

DOI: https://doi.org/10.1007/s10803-016-2865-7 
This manuscript was published as:

Kirchner, J., Ruch, W., \& Dziobek, I. (2016). Brief report: Character strengths in adults with autism spectrum disorder without intellectual impairment. Journal of Autism and Developmental Disorders, 46(10), 3330-3337. doi:10.1007/s10803-016-2865-7 
Character strengths in adults with autism spectrum disorder without intellectual impairment

\author{
Jennifer Kirchner (1, 2), Willibald Ruch (3), Isabel Dziobek (1, 2) \\ (1) Cluster of Excellence Languages of Emotion, Freie Universität Berlin, Berlin, Germany \\ (2) Berlin School of Mind and Brain, Humboldt-Universität zu Berlin, Berlin, Germany \\ (3) Universität Zürich, Zürich, Switzerland
}

\title{
Contact Information:
}

Corresponding Author:

Name: Jennifer Kirchner

Address: Berlin School of Mind and Brain, Humboldt-Universität Berlin, Luisenstraße 56, 10117 Berlin

E-mail: jennifer.kirchner@hu-berlin.de

Tel. +49(0)30 2093-1738

Fax $+49(0) 30$ 2093-1802

Name: Prof. Dr. Willibald Ruch

Address: Universität Zürich, Department of Psychology-Personality and Assessment, Binzmühlestrasse 14/7, CH-8050 Zürich

Name: Prof. Dr. Isabel Dziobek

Address: Berlin School of Mind and Brain, Humboldt-Universität zu Berlin, Luisenstraße 56, 10117 Berlin

Running Head: Character strengths in autism 


\title{
Character strengths in adults with autism spectrum disorder without intellectual impairment
}

\begin{abstract}
In the current study, we assessed character strengths in individuals with autism spectrum disorder (ASD, $\mathrm{n}=32$ ) and neurotypical controls $(\mathrm{n}=32)$ using the Values in Action Inventory (VIA-IS, Peterson \& Seligman, 2004) and explored associations with levels of satisfaction with life (SWL). The most frequently endorsed signature strengths (i.e., five topranked strengths within an individual's strength ranking) were emotional (humour, love) and interpersonal strengths (kindness, fairness) in the control group, the most frequently endorsed signature strengths in the ASD group were intellectual strengths (open-mindedness, creativity, love of learning). Interpersonal and emotional strengths had, however, the highest positive associations with SWL in the ASD group.
\end{abstract}

Keywords: autism spectrum disorder, adults, character strengths, satisfaction with life 


\section{Character strengths in adults with autism spectrum disorder without intellectual}

\section{impairment}

In the last decades, the interest in studying resources and strengths in individuals with autism spectrum disorder (ASD), in contrast to the mere study of symptoms and deficits, has grown. This is especially relevant because outcomes (e.g., satisfaction with life, employment) in adults with ASD are often poor and rates of comorbid depression are high (Howlin \& Moss, 2012). Strengths-focused research can inform interventions targeting improvements of outcomes in adults with ASD. Strengths in some individuals with ASD have been described so far in three different contexts: 1) abilities related to a specific cognitive style (Dawson, Soulières, Gernsbacher, \& Mottron, 2007), 2) skills related to special interests (Kirchner \& Dziobek, 2014) and 3) positive aspects related to personality and character (Preißmann, 2014).

In the current paper, we sought to address the third area of potential strengths in ASD, namely those related to personality characteristics. There are anecdotal descriptions of individuals with ASD having certain strengths associated with their personality, such as being fair, authentic and reliable (Preißmann, 2014). Also Tony Attwood (1999) described individuals with ASD as loyal friends who speak their mind "irrespective of social context or adherence to personal beliefs", are free of sexist, ageist, or culturalist biases and have an inherent determination to seek the truth. There have been scientific attempts to describe personality beyond mere psychopathology in ASD (Ozonoff, Garcia, Clark, \& Lainhart, 2005; Strunz et al., 2014); however, the focus was often on weaknesses rather than strengths (Schriber, Robins, \& Solomon, 2014).

A new perspective on personality is taken by positive psychology, which offers a theoretical framework to study character strengths as supplement to the study of deficits and disorders in traditional psychology (Park \& Peterson, 2009). Character strengths are defined as positively 
valued trait-like individual differences, which manifest in individuals' thoughts, feelings, and behaviours across different situations and are stable over time. In a first study comparing individuals with ASD and neurotypical (i.e., non-autistic) controls regarding their character strengths with the VIA-IS, Samson and Antonelli (2013) found the ASD group to score mostly lower on emotional and interpersonal character strengths but as high on most intellectual strengths and strengths of restraint as the control group. However, rather than only comparing magnitudes of character strengths of individuals with ASD to a norm population (Samson \& Antonelli, 2013), it was suggested that in vulnerable populations it is more warranted to examine an individual's strengths relative to his/her other strengths of character (Park \& Peterson, 2009). With this individual strength-based approach, the focus is on those strengths, which the individual possesses rather than on differences from others. In particular, the five top-ranked strengths in one's strength ranking, also referred to as signature strengths, have received growing research attention, as they are considered to be the most salient to a person (Peterson \& Seligman, 2004; Ruch et al., 2010).

Another influential line of research regarding character strengths provides growing empirical evidence in neurotypical individuals, that the endorsement of character strengths is positively associated with satisfaction with life (SWL) (Littman-Ovadia \& Lavy, 2012). It has been shown that training those character strengths which were associated with SWL - compared to others which were not- improves SWL (Proyer, Ruch, \& Buschor, 2013). However, groups of individuals (e.g., different cultures/occupations/genders) seem to differ regarding which character strengths are most strongly associated with SWL (Littman-Ovadia \& Lavy, 2012; Peterson et al., 2007).

In the current study we (1) assessed character strengths in individuals with ASD and neurotypical controls, (2) examined which character strengths are most often signature 
strengths in individuals with ASD and explored differences from controls and (3) explored associations between character strengths and SWL in individuals with ASD and controls.

\section{Methods}

\section{Participants}

Thirty-two adults with ASD without intellectual impairment and 32 matched (gender, age, education and employment status) neurotypical controls were included in the study. Subjects with ASD were recruited through the autism outpatient clinic of the Charité - University Medicine Berlin or were referred by specialized cooperating clinicians. All participants were diagnosed with an ASD according to DSM-IV (American Psychiatric Association, 2000) using the Autism Diagnostic Observation Schedule (ADOS, Bölte \& Poustka, 2004) and a semi-structured clinical interview based on the Diagnostic and Statistical Manual of Mental Disorders, 4th edition (DSM-IV, American Psychiatric Association, 2000). Assessment was done by a trained clinical psychologist and a specialized medical doctor. For demographic data, see Table 1.

\section{[Insert Table 1 here]}

\section{Measures}

The Values in Action Inventory of Strengths (VIA-IS, Peterson \& Seligman, 2004) is a selfreport questionnaire assessing 24 character strengths, which can be assigned to five factors (emotional, interpersonal, intellectual and theological strengths, as well as strengths of restraint) (Ruch et al., 2010). For the VIA-IS character strengths and descriptions, see Table 2. Each scale consists of ten items. In total the VIA-IS contains 240 items, which are rated using a five-point Likert scale ( $1=$ "very much unlike me" to $5=$ "very much like me"). An example item for the character strength persistence is "I never quit a task before it is done". Mean scores for the scales are calculated. In this study, the German version of the VIA-IS was used (Ruch et al., 2010). It demonstrated to be reliable and valid: internal consistencies of the 
scales ranged from Cronbach's $\alpha=.71$ to .90 (Ruch et al., 2010). In our study, internal consistencies of the scales ranged from Cronbach's $\alpha=.70$ to .91 (ASD) and $\alpha=.84$ to .93 (controls)

[Insert Table 2 here]

The Satisfaction with Life Scale (SWLS: Diener, Emmons, Larsen, \& Griffin, 1985) is a fiveitem instrument measuring global life satisfaction using a seven-point Likert scale ( $1=$ "strongly disagree" to $7=$ "strongly agree"). An example item is "I am satisfied with my life". A mean score is calculated. The SWLS is widely used in research and has shown strong internal reliability (Cronbach's $\alpha=.87$ ) (Diener et al. 1985) and good discriminant validity (Pavot \& Diener, 1993). In the present study, Cronbach's $\alpha$ were .80 (ASD) and $\alpha=.88$ (controls).

\section{Procedure}

Participants with ASD completed the questionnaires online and received $15 €$. A matched control group was randomly selected from a large data pool which were collected through the website www.charakterstaerken.org hosted by the University of Zurich]. All questionnaires were completed anonymously. All parts of the study were conducted according to the declaration of Helsinki and following local ethical standards. All subjects provided written informed consent. Statistical analyses were performed with the statistical software IBM SPSS 22. Accounting for multiple testing, corrected levels of significance were administered using the false discovery rate procedure proposed by Benjamini and Hochberg (1995).

\section{Results}

\section{Group comparisons mean scores VIA-IS}

Multivariate analysis of variance with the 24 scales of the VIA-IS as dependent variables and group (ASD / control) as the fixed factor were computed. All assumptions for conducting a MANOVA were met. There was a significant main effect of group, indicating 
that individuals with ASD and controls differed regarding the endorsement of character strengths, $F(24,39)=5.36, p<.001$; Wilk's $\Lambda=0.23$, partial $\eta^{2}=.77$. For a full display of results, see Table 3 .

\section{[Insert Table 3 here]}

\section{Ipsative ranking and signature strengths}

We assigned ipsative ranks to individual strengths scores, from 1 (highest) to 24 (lowest), resulting in a specific ranking order for each participant. Based on that ranking, we identified the five most highly ranked strengths for each individual (which are referred to as signature strengths) and calculated percentages for how often a certain strength belonged to the signature strengths in each group (see Table 4).

To reveal group differences between these percentages, we conducted chi-square tests (see Littman-Ovadia \& Lavy, 2012) for those strengths that were ranked within the top five for at least one of the groups (open-mindedness, authenticity, love of learning, creativity, fairness, humour, kindness, love). Creativity was significantly more often a signature strength $\operatorname{ASD}\left(\chi^{2}(1, N=64)=5.74, p=.02\right)$ than in controls, while love $\left(\chi^{2}(1, N=64)=5.85, p=\right.$ $.02)$ and humour $\left(\chi^{2}(1, N=64)=10.47, p<.01\right)$ were significantly more often signature strengths in controls. There were no significant differences between groups regarding the other character strengths.

[Insert Table 4 here] 


\section{Satisfaction with life and character strengths}

Satisfaction with life was significantly lower in ASD $(M=2.9, S D=1.2)$ than in controls $(M=4.5, S D=1.4), t(62)=4.76, p<.001)$. Pearson correlations with the 24 character strengths of the VIA-IS and the SWLS were conducted. Descriptively, the two groups had the strongest associations between hope and zest with SWL, respectively. In addition, kindness, social intelligence, teamwork and humour were most strongly related to SWL in ASD, while for controls persistence, curiosity, perspective, and humour were most strongly correlated with SWL. For a complete display of correlations, see Table 5.

[Insert Table 5 here]

\section{Discussion}

\section{Endorsement of character strengths}

The ASD group scored mostly lower on those character strengths that can be classed as interpersonal (e.g., teamwork, kindness) and emotional (e.g., social intelligence, love) strengths but did not differ from controls on most intellectual strengths and strengths of restraint, which is in line with Samson and Antonelli (2013). This also corroborates a study from Strunz and colleagues (2014), who assessed individuals with ASD without intellectual impairment using the NEO Personality Inventory-Revised (NEO-PI-R) and found them to be as intellectually curious, as dutiful and to strive as much for achievements as controls. We found open-mindedness to be the highest ranked character strength in ASD, but in contrast to Samson and Antonelli (2013) we did not find individuals with ASD to score higher on openmindedness than controls.

\section{Signature strengths}

In ASD, the most frequent signature strengths were open-mindedness (intellectual strengths), authenticity (strength of restraint), love of learning (intellectual strength) 
creativity (intellectual strength), and fairness (interpersonal strength). In comparison, openmindedness (intellectual strength), fairness (interpersonal strength), humour (emotional strength), kindness (interpersonal strength) and love (emotional strength) were most often in the signature strengths profile of controls.

Individuals who score high on open-mindedness think things through, examine aspects from all sides, weigh the pros and cons carefully and do not jump to conclusions impulsively (Harzer \& Ruch, 2014). Following the theory of systemizing (Baron-Cohen, Richler, Bisarya, Gurunathan, \& Wheelwright, 2003), individuals with ASD seek to discover the "truth" by looking for lawful patterns and they are more likely to base their judgment on rules (e.g., weighing pros and cons) rather than on information which comes from empathizing (BaronCohen, 2009). Also, fairness and authenticity, which are within the most typical signature strengths in individuals with ASD, can be facilitated by the trend to systemize. Fairness consists of treating all people the same according to principles of fairness and justice, and individuals who endorse the character strength authenticity speak the truth and present themselves in a genuine way (Harzer \& Ruch, 2014). There are anecdotal reports that individuals with ASD adhere to social rules in a deterministic way (such as sharing things equally or telling the truth). More evidence towards strengths in authenticity and fairness in individuals with ASD comes from other studies. Izuma and colleagues (2011) found individuals with ASD to be less likely to adapt their behaviour in order to improve their social reputation than neurotypical controls and we found individuals with ASD to have fewer social stereotypes against ethnic minorities compared to a neurotypical control group (Kirchner, Schmitz, \& Dziobek, 2012). Another character strength belonging to the most frequent signature strengths in individuals with ASD - and significantly more often than in controls was creativity. Individuals who endorse creativity as a character strength consider themselves as original thinkers and like to come up with new and different ideas (Harzer \& Ruch, 2014). Empirical evidence regarding creativity being a strength in individuals with ASD comes from 
a study from Liu and colleagues (2011), who found them to score higher on originality and elaboration. In addition, in a previous study we identified creativity as the second most common approach in pursuing one's special interest (after systemizing) in individuals with ASD (Kirchner \& Dziobek, 2014). The fifth character strength, which belonged to the most common signature strengths in individuals with ASD, was love of learning, which comprises the eagerness to master new skills, topics and bodies of knowledge (Harzer \& Ruch, 2014). Already Asperger (1944) described individuals with ASD to be able to acquire an astonishing body of knowledge in their special interests, often through self-guided studying.

\section{Character strengths and satisfaction with life}

Interestingly, we found hope, zest, kindness, humour, social intelligence and teamwork (all emotional or interpersonal strengths) to have the strongest positive associations with SWL in the ASD group. This is in contrast to Samson and Antonelli (2013), who found only hope to be associated with SWL in $\mathrm{ASD}^{1}$. One possible interpretation is that higher levels of emotional and interpersonal strengths contribute to higher SWL in ASD, which would underline the importance of training social and emotional competencies in this population. In line with that, Mazurek and colleagues (2014) found loneliness to be associated with decreased levels of SWL in ASD, while greater quantity and quality of friendships were associated with decreased loneliness.

In addition to the importance of certain character strengths for SWL, it is also fruitful to consider the fit between environment and tasks (e.g., at work) with the character strengths of an individual. For example, Harzer \& Ruch (2012) found neurotypical individuals who applied their signature strengths at work to report more positive experiences. Thus future studies should evaluate how exercising character strengths, and signature strengths in

\footnotetext{
${ }^{1}$ Controls in our and Samson and Antonellis study (2013) had comparable associations between character strengths and SWL with previous work (Peterson et al., 2007; Ruch et al., 2010), (i.e., hope, zest, persistence, perspective were among those character strengths with the strongest associations with SWL).
} 
particular, can contribute to the improvement of outcomes (e.g., SWL, work satisfaction, etc.) in ASD.

The results of this study should be interpreted with the following limitations in mind: All collected data are self-reported data. For future studies we recommend to also use a peerrating form for the character strengths questionnaire (Ruch et al., 2010). The size of our research sample was relatively small, which limits the generalization of the findings. Furthermore, we might have missed effects between groups due to limited statistical power and no causational inferences can be drawn due to the cross-sectional design of our study. 


\section{References}

American Psychiatric Association. (2000). DSM-IV. Diagnostic and Statistical Manual of Mental Disorders 4th edition TR. American Psychological Associaton.

Asperger, H. (1944). Die „, Autistischen Psychopathen “ im Kindesalter. Archiv Für Psychiatrie Und Nervenkrankheiten, 117, 73-136.

Attwood, T., \& Gray, C. (1999). The Discovery of "Aspie" Criteria. The Morning News, 11(3). Retrieved from

http://www.tonyattwood.com.au/index.php/component/content/article?id=79:thediscovery-of-aspie-criteria

Baron-Cohen, S. (2009). Autism: the empathizing-systemizing (E-S) theory. Annals of the New York Academy of Sciences, 1156, 68-80. doi:10.1111/j.1749-6632.2009.04467.x

Baron-Cohen, S., Richler, J., Bisarya, D., Gurunathan, N., \& Wheelwright, S. (2003). The systemizing quotient: an investigation of adults with Asperger syndrome or highfunctioning autism, and normal sex differences. Philosophical Transactions of the Royal Society of London. Series B, Biological Sciences, 358(1430), 361-74.

doi:10.1098/rstb.2002.1206

Benjamini, Y., \& Hochberg, Y. (1995). Controlling the False Discovery Rate: A Practical and Powerful Approach to Multiple Testing. Journal of the Royal Statistical Society, 57(1), 289-300.

Bölte, S., \& Poustka, F. (2004). Diagnostische Beobachtungsskala für Autistische Störungen (ADOS): Erste ergebnisse zur zuverlässigkeit und gültigkeit. Zeitschrift Fur Kinder- Und Jugendpsychiatrie Und Psychotherapie, 32(1), 45-50. doi:10.1024/1422-4917.32.1.45

Dawson, M., Soulières, I., Gernsbacher, M. A., \& Mottron, L. (2007). The level and nature of autistic intelligence. Psychological Science, 18, 657-662. doi:10.1111/j.14679280.2007.01954.x

Diener, E., Emmons, R.A., Larsen, R.J., \& Griffin, S. (1985). The satisfaction with life scale. Journal of Personality Assessment, 49, 71-75.

Harzer, C., \& Ruch, W. (2012). When the job is a calling: The role of applying one's signature strengths at work. The Journal of Positive Psychology, 7(5), 362-371. doi:10.1080/17439760.2012.702784

Harzer, C., \& Ruch, W. (2014). The Role of Character Strengths for Task Performance , Job Dedication, Interpersonal Facilitation, and Organizational Support The Role of Character Strengths for Task Performance, Job Dedication, Interpersonal Facilitation, and Organizational Support, (July), 37-41. doi:10.1080/08959285.2014.913592

Howlin, P., \& Moss, P. (2012). Adults with autism spectrum disorders. Canadian Journal of Psychiatry. Revue Canadienne de Psychiatrie, 57(5), 275-83. Retrieved from http://www.ncbi.nlm.nih.gov/pubmed/22825929 
Izuma, K., Matsumoto, K., Camerer, C. F., \& Adolphs, R. (2011). Insensitivity to social reputation in autism. Proceedings of the National Academy of Sciences.

Kirchner, J. C., \& Dziobek, I. (2014). Toward the Successful Employment of Adults with Autism : A First Analysis of Special Interests and Factors Deemed Important for Vocational Performance. Scandinavian Journal of Child and Adolescent Psychiatry and Psychologytry and Psychology, 2(2), 77-85.

Kirchner, J. C., Schmitz, F., \& Dziobek, I. (2012). Brief report: stereotypes in autism revisited. Journal of Autism and Developmental Disorders, 42(10), 2246-51. doi:10.1007/s 10803-012-1460-9

Littman-Ovadia, H., \& Lavy, S. (2012). Differential ratings and associations with well-being of character strengths in two communities. Health Sociology Review, 21(3), 299-312.

Liu, M.-J., Shih, W.-L., \& Ma, L.-Y. (2011). Are children with Asperger syndrome creative in divergent thinking and feeling? A brief report. Research in Autism Spectrum Disorders, 5(1), 294-298. doi:10.1016/j.rasd.2010.04.011

Mazurek, M. O. (2014). Loneliness, friendship, and well-being in adults with autism spectrum disorders. Autism : The International Journal of Research and Practice, 18, 223-32. doi:10.1177/1362361312474121

Ozonoff, S., Garcia, N., Clark, E., \& Lainhart, J. E. (2005). MMPI-2 personality profiles of high-functioning adults with autism spectrum disorders. Assessment, 12(1), 86-95. doi:10.1177/1073191104273132

Park, N., \& Peterson, C. (2009). Character strengths: Research and practice. Journal of College and Character, $X(4), 1-10$. Retrieved from http://www.degruyter.com/view/j/jcc.2009.10.4/jcc.2009.10.4.1042/jcc.2009.10.4.1042.x $\mathrm{ml}$

Pavot, W., \& Diener, E. (1993). Review of the Satisfaction With Life Scale. Psychological Assessment, 5(2), 164-172. doi:10.1037/1040-3590.5.2.164

Peterson, C., Ruch, W., Beermann, U., Park, N., \& Seligman, M. E. P. (2007). Strengths of character, orientations to happiness, and life satisfaction. The Journal of Positive Psychology, 2(January 2015), 149-156. doi:10.1080/17439760701228938

Peterson, C., \& Seligman, M. E. (2004). Character strengths and virtues: A handbook and classification (pp. 53-89). New York: Oxford University Press and Washington: American Psychological Association.

Preißmann, C. (2014). Stärkentraining eröffnet Perspektiven. Ergopraxis, (9), 38-41.

Proyer, R. T., Ruch, W., \& Buschor, C. (2013). Testing Strengths-Based Interventions: A Preliminary Study on the Effectiveness of a Program Targeting Curiosity, Gratitude, Hope, Humor, and Zest for Enhancing Life Satisfaction. Journal of Happiness Studies, 14, 275-292. doi:10.1007/s10902-012-9331-9 
Ruch, W., Proyer, R. T., Harzer, C., Park, N., Peterson, C., \& Seligman, M. E. P. (2010). Values in Action Inventory of Strengths (VIA-IS) Adaptation and Validation of the German Version and the Development of a Peer-Rating Form. Journal of Individual Differences, 31(3), 138-149. doi:10.1027/1614-0001/a000022

Samson, A. C., \& Antonelli, Y. (2013). Humor as character strength and its relation to life satisfaction and happiness in Autism Spectrum Disorders. Humor, 26(3), 477-491. Retrieved from http://www.degruyter.com/view/j/humr.2013.26.issue-3/humor-20130031/humor-2013-0031.xml

Schriber, R. a, Robins, R. W., \& Solomon, M. (2014). Personality and self-insight in individuals with autism spectrum disorder. Journal of Personality and Social Psychology, 106(1), 112-30. Retrieved from http://www.ncbi.nlm.nih.gov/pubmed/24377361

Shimai, S., Otake, K., Park, N., Peterson, C., \& Seligman, M. E. P. (2006). Convergence of Character Strengths in American and Japanese Young Adults. Journal of Happiness Studies, 7(3), 311-322. doi:10.1007/s10902-005-3647-7

Strunz, S., Westphal, L., Ritter, K., Heuser, I., Dziobek, I., \& Roepke, S. (2014). Personality Pathology of Adults With Autism Spectrum Disorder Without Accompanying Intellectual Impairment in Comparison to Adults With Personality Disorders. Journal of Autism and Developmental Disorders. doi:10.1007/s10803-014-2183-x 
Table 1

Demographics

\begin{tabular}{llll}
\hline & ASD & Control & $p$ \\
\hline Gender (male/female) & $21 / 11$ & $20 / 12$ & $.79^{\mathrm{b}}$ \\
Age (years) & $30.9 \pm 8.4$ & $30.9 \pm 8.4$ & $.99^{\mathrm{a}}$ \\
Education (years) & $14.0 \pm 2.9$ & $13.8 \pm 2.9$ & $.70^{\mathrm{a}}$ \\
Nationality (German / Austrian /Swiss) & $(32 / 0 / 0)$ & $(19 / 11 / 2)$ & $<.001^{\mathrm{b}}$ \\
Housing* & $(11 / 4 / 3 / 11 / 3)$ & $(10 / 11 / 5 / 6 / 0)$ & $.08^{\mathrm{b}}$ \\
Relationship status** & $(6 / 24 / 2)$ & $(10 / 20 / 2)$ & $.50^{\mathrm{b}}$ \\
Currently working (Yes/No) & $11 / 21$ & $12 / 20$ & $.79^{\mathrm{b}}$ \\
Satisfaction with Life (SWLS) & $2.9 \pm 1.2$ & $4.5 \pm 1.4$ & $.00^{\mathrm{a}}$ \\
\hline
\end{tabular}

$p$ values reflect level of significance from t-test for independent samples ${ }^{a}$ and chi-square ${ }^{b}$.

Values are given in mean \pm SD.

*Housing (alone / with spouse / shared apartment / with parents / other)

${ }^{* *}$ Relationship status (married / single / divorced) 
Table 2

The 24 Character Strengths included in the Values in Action Classification of Strengths (VIA-IS, Peterson \& Seligman, 2004) and short descriptions (Ruch et al. 2010, Harzer \& Ruch, 2014)

\begin{tabular}{|c|c|}
\hline \multicolumn{2}{|c|}{ Emotional Strengths } \\
\hline (VIA 9) & Zest (enthusiasm): Approaching life with excitement and energy \\
\hline (VIA 22) & Hope (optimism): Expecting the best and working to achieve it \\
\hline (VIA 6) & Bravery (courage): Not shrinking from threat, challenge, difficulty or pain \\
\hline (VIA 23) & Humour (playfulness): Liking to laugh and joke, bringing smiles to other people \\
\hline (VIA 10) & Love: Capacity to love and be loved, valuing close relations with others \\
\hline (VIA 12) & $\begin{array}{l}\text { Social Intelligence: Being aware of the motives and feelings of self and others, knowing } \\
\text { what to do to fit into different social situations }\end{array}$ \\
\hline \multicolumn{2}{|c|}{ Interpersonal Strengths } \\
\hline (VIA 11) & $\begin{array}{l}\text { Kindness (generosity): Doing favours and good deeds for others, helping others and } \\
\text { taking care }\end{array}$ \\
\hline (VIA 13) & Teamwork: Working well as a member of a group or team, being loyal to the group \\
\hline (VIA 14) & Fairness: Treating all people the same according to notions of fairness and justice \\
\hline (VIA 15) & $\begin{array}{l}\text { Leadership: Taking care of a group and its members, organizing activities and seeing that } \\
\text { they happen }\end{array}$ \\
\hline (VIA 16) & Forgiveness: Forgiving those who have done wrong, giving people a second chance \\
\hline (VIA 17) & $\begin{array}{l}\text { Modesty: Letting one's accomplishments speak for themselves, not regarding oneself as } \\
\text { more special than one is }\end{array}$ \\
\hline \multicolumn{2}{|c|}{ Intellectual Strengths } \\
\hline (VIA 1) & $\begin{array}{l}\text { Creativity (originality): Thinking of novel and productive ways to do things, including } \\
\text { but not limited to artistic achievements }\end{array}$ \\
\hline (VIA 2) & $\begin{array}{l}\text { Curiosity (interest:) Taking an interest in all of ongoing experience, findings subjects and } \\
\text { topics fascinating, exploring and discovering }\end{array}$ \\
\hline (VIA 3) & $\begin{array}{l}\text { Open-Mindedness (judgement): Thinking things through and examining them from all } \\
\text { sides, not jumping to conclusions; being able to change one's mind in light of evidence }\end{array}$ \\
\hline (VIA 4) & Love of Learning: Enjoyment of mastering new skills, topics, and bodies of knowledge \\
\hline
\end{tabular}

Strengths of Restraint

(VIA 7) Persistence (perseverance): Finishing what one starts, persisting in a course of action in spite of obstacles

(VIA 18) Prudence: Being careful about one's choices; not saying or doing things that might later be regretted

(VIA 19) Self-regulation: Regulating what one feels and does

(VIA 5) Perspective: Being able to provide wise counsel to others, having ways of looking at the world that make sense to oneself and to other people

(VIA 8) Authenticity (honesty): Speaking the truth and presenting oneself in a genuine way

\begin{tabular}{ll}
\hline Theological Strengths \\
\hline (VIA 24) & $\begin{array}{l}\text { Spirituality (religiousness): Having coherent beliefs about the higher purpose and } \\
\text { meaning of life }\end{array}$ \\
(VIA 21) & $\begin{array}{l}\text { Gratitude: Being aware of and thankful for the good things that happen } \\
\text { (VIA 20) }\end{array}$ \\
& $\begin{array}{l}\text { Appreciation of beauty: Noticing and appreciating beauty, excellence, and/or skilled } \\
\text { performance in all domains of life }\end{array}$ \\
\hline
\end{tabular}


Table 3

Character strengths in individuals with ASD and neurotypical control individuals

\begin{tabular}{|c|c|c|c|c|c|c|c|c|c|c|c|c|}
\hline \multicolumn{2}{|l|}{ Emotional Strengths } & \multirow{2}{*}{$\frac{\mathbf{M}}{2.91}$} & \multirow{2}{*}{$\frac{\text { SD }}{0.72}$} & \multirow{2}{*}{$\frac{95 \% \text { CI }}{[2.66,3.16]}$} & $\mathbf{p}$ & \multicolumn{2}{|c|}{ Intellectual Strengths } & & \multirow{2}{*}{$\frac{\bar{M}}{3.5}$} & SD & $95 \%$ CI & \multirow{2}{*}{$\frac{p}{.645}$} \\
\hline (VIA 9) Zest & $\mathrm{ASD}$ & & & & $.004 \%$ & (VIA 1) & Creativity & ASD & & 0.63 & {$[3.27,3.75]$} & \\
\hline & Control & 3.43 & 0.68 & {$[3.18,3.68]$} & & & & Control & 3.43 & 0.72 & {$[3.19,3.67]$} & \\
\hline \multirow{2}{*}{ (VIA 22) Hope } & ASD & 2.85 & 0.78 & {$[2.57,3.13]$} & $.004 \%$ & (VIA 2) & Curiosity & ASD & 3.25 & 0.69 & {$[3.02,3.47]$} & $.005 *$ \\
\hline & Control & 3.44 & 0.79 & {$[3.16,3.71]$} & & & & Control & 3.72 & 0.59 & {$[3.49,3.95]$} & \\
\hline (VIA 6) & ASD & 3.15 & 0.65 & {$[2.93,3.38]$} & .103 & (VIA 3) & Open-Mindedness & ASD & 3.73 & 0.60 & {$[3.52,3.93]$} & .323 \\
\hline & Control & 3.42 & 0.63 & {$[3.19,3.65]$} & & & & Control & 3.87 & 0.55 & {$[3.67,4.07]$} & \\
\hline (VIA 23) Humour & ASD & 2.99 & 0.64 & {$[2.76,3.22]$} & $<.001 *$ & (VIA 4) & Love of Learning & ASD & 3.48 & 0.77 & {$[3.23,3.72]$} & .172 \\
\hline & Control & 3.79 & 0.64 & {$[3.57,4.02]$} & & & & Control & 3.72 & 0.62 & {$[3.47,3.96]$} & \\
\hline (VIA 10) Love & ASD & 2.88 & 0.61 & {$[2.63,3.12]$} & $<.001 *$ & \multicolumn{3}{|c|}{ Strengths of Restraint } & $\mathbf{M}$ & SD & $95 \% \mathrm{CI}$ & $\mathbf{p}$ \\
\hline & Control & 3.69 & 0.76 & {$[3.44,3.93]$} & & \multirow{2}{*}{\multicolumn{2}{|c|}{ (VIA 7) Persis }} & $\mathrm{ASD}$ & 3.08 & 0.83 & {$[2.80,3.36]$} & .097 \\
\hline (VIA 12) Social & ASD & 2.42 & 0.53 & {$[2.22,2.62]$} & $<.001 *$ & & & Control & 3.41 & 0.74 & {$[3.14,3.69]$} & \\
\hline Intelligence & Control & 3.65 & 0.61 & {$[3.45,3.85]$} & & \multirow[t]{2}{*}{ (VIA 18) } & \multirow[t]{2}{*}{ Prudence } & ASD & 3.29 & 0.57 & {$[3.11,3.48]$} & .852 \\
\hline \multicolumn{2}{|l|}{ Interpers onal Strengths } & $\mathbf{M}$ & SD & $95 \% \mathrm{CI}$ & $\mathbf{p}$ & & & Control & 3.32 & 0.49 & {$[3.13,3.51]$} & \\
\hline \multirow[t]{2}{*}{ (VIA 11) Kindness } & $\mathrm{ASD}$ & 3.05 & 0.69 & {$[2.83,3.27]$} & $<.001 *$ & \multirow[t]{2}{*}{ (VIA 19) } & \multirow[t]{2}{*}{ Self-regulation } & ASD & 2.99 & 0.64 & {$[2.76,3.22]$} & .146 \\
\hline & Control & 3.88 & 0.53 & {$[3.66,4.09]$} & & & & Control & 3.23 & 0.65 & {$[2.30,3.45]$} & \\
\hline \multirow[t]{2}{*}{ (VIA 13) Teamwork } & ASD & 3.00 & 0.63 & {$[2.79,3.21]$} & $<.001 *$ & \multirow[t]{2}{*}{ (VIA 5) } & \multirow[t]{2}{*}{ Perspective } & ASD & 3.01 & 0.62 & {$[2.80,3.22]$} & $<.001 *$ \\
\hline & Control & 3.66 & 0.56 & {$[3.45,3.87]$} & & & & Control & 3.60 & 0.56 & {$[3.39,3.81]$} & \\
\hline (VIA 14) Fairness & ASD & 3.43 & 0.63 & {$[3.23,3.63]$} & $.001 *$ & \multirow[t]{2}{*}{ (VIA 8) } & \multirow[t]{2}{*}{ Authenticity } & ASD & 3.64 & 0.49 & {$[3.48,3.80]$} & .188 \\
\hline & Control & 3.90 & 0.49 & {$[3.70,4.10]$} & & & & Control & 3.79 & 0.43 & {$[3.63,3.95]$} & \\
\hline (VIA 15) Leadership & ASD & 2.79 & 0.74 & {$[2.56,3.01]$} & $<.001 *$ & Theologic & al Strengths & & $\mathbf{M}$ & SD & $95 \% \mathrm{CI}$ & $\mathbf{p}$ \\
\hline & Control & 3.62 & 0.52 & {$[3.39,3.84]$} & & (VIA 24) & Spirituality & $\mathrm{ASD}$ & 2.04 & 0.80 & {$[1.73,2.35]$} & .013 \\
\hline (VIA 16) Forgiveness & ASD & 2.81 & 0.67 & {$[2.59,3.03]$} & $<.001 *$ & & & Control & 2.60 & 0.93 & {$[2.29,2.90]$} & \\
\hline & Control & 3.46 & 0.59 & {$[3.24,3.69]$} & & (VIA 21) & Gratitude & ASD & 2.90 & 0.62 & {$[2.69,3.10]$} & $<.001 *$ \\
\hline (VIA 17) Modesty & ASD & 3.19 & 0.59 & {$[2.99,3.39]$} & .947 & & & Control & 3.55 & 0.54 & {$[3.34,3.76]$} & \\
\hline & Control & 3.20 & 0.53 & {$[3.00,3.40]$} & & (VIA 20) & Appreciation of & ASD & 3.11 & 0.72 & {$[2.88,3.35]$} & .011 \\
\hline & & & & & & & beauty & Control & 3.54 & 0.59 & {$[3.31,3.78]$} & \\
\hline
\end{tabular}


Table 4

Ranking of signature strengths

\begin{tabular}{|c|c|c|c|c|c|c|c|c|c|}
\hline \multirow{2}{*}{\multicolumn{2}{|c|}{$\overline{\text { VIA-IS Skala }}$}} & \multicolumn{5}{|l|}{ ASD } & \multicolumn{3}{|c|}{ Control } \\
\hline & & Rank & $\mathbf{N}$ & $\%$ & VIA-IS & Skala & Rank & $\mathbf{N}$ & $\%$ \\
\hline VIA 3 & Open-Mindedness & 1 & 20 & 63 & VIA 3 & Open-Mindedness & 2 & 16 & 50 \\
\hline VIA 8 & Authenticity & 2 & 19 & 59 & VIA 14 & Fairness & 2 & 16 & 50 \\
\hline VIA 4 & Love of Learning & 3 & 17 & 53 & VIA 23 & Humour & 2 & 16 & 50 \\
\hline VIA 1 & Creativity & 4 & 15 & 47 & VIA 11 & Kindness & 4 & 12 & 38 \\
\hline VIA 14 & Fairness & 5 & 11 & 34 & VIA 10 & Love & 5 & 11 & 34 \\
\hline VIA 18 & Prudence & 6 & 10 & 31 & VIA 2 & Curiosity & 6 & 10 & 31 \\
\hline VIA 6 & Bravery & 8 & 9 & 28 & VIA 4 & Love of Learning & 7,5 & 9 & 28 \\
\hline VIA 7 & Persistence & 8 & 9 & 28 & VIA 13 & Teamwork & 7,5 & 9 & 28 \\
\hline VIA 17 & Modesty & 8 & 9 & 28 & VIA 21 & Gratitude & 9 & 8 & 25 \\
\hline VIA 2 & Curiosity & 10 & 8 & 25 & VIA 7 & Persistence & 11 & 7 & 22 \\
\hline VIA11 & Kindness & 11 & 7 & 22 & VIA 8 & Authenticity & 11 & 7 & 22 \\
\hline VIA 5 & Perspective & 12 & 6 & 19 & VIA 12 & Social Intelligence & 11 & 7 & 22 \\
\hline VIA 20 & Appreciation of beauty & 13,5 & 5 & 16 & VIA 20 & Appreciation of beauty & 13,5 & 6 & 19 \\
\hline VIA 13 & Teamwork & 13,5 & 5 & 16 & VIA 1 & Creativity & 13,5 & 6 & 19 \\
\hline VIA 23 & Humour & 15 & 4 & 13 & VIA 22 & Hope & 15,5 & 5 & 16 \\
\hline VIA 9 & Zest & 18 & 3 & 9 & VIA 5 & Perspective & 15,5 & 5 & 16 \\
\hline VIA 10 & Love & 18 & 3 & 9 & VIA 6 & Bravery & 19 & 4 & 13 \\
\hline VIA 19 & Self-regulation & 18 & 3 & 9 & VIA 15 & Leadership & 19 & 4 & 13 \\
\hline VIA 21 & Gratitude & 18 & 3 & 9 & VIA 17 & Persistence & 19 & 4 & 13 \\
\hline VIA 22 & Hope & 18 & 3 & 9 & VIA 18 & Prudence & 19 & 4 & 13 \\
\hline VIA 16 & Forgiveness & 21 & 2 & 6 & VIA 19 & Self-regulation & 19 & 4 & 13 \\
\hline VIA 24 & Spirituality & 22 & 1 & 3 & VIA 9 & Zest & 23 & 3 & 9 \\
\hline VIA 12 & Social Intelligence & 23,5 & 0 & 0 & VIA 16 & Forgiveness & 23 & 3 & 9 \\
\hline VIA 15 & Leadership & 23,5 & 0 & 0 & VIA 24 & Spirituality & 23 & 3 & 9 \\
\hline
\end{tabular}

Rank, $\mathrm{N}$ and \% refer to how often the character strength was within the top-five character strengths of an individual in the respective group (ASD/Control) 
Table 5

Correlations between VIA-IS character strengths and SWLS

\begin{tabular}{|c|c|c|c|c|}
\hline & ASD & $p$ & Control & $p$ \\
\hline VIA-22 Hope & $.672 *[.413, .857]$ & $<.001$ & $.787 *[.622, .893]$ & $<.001$ \\
\hline VIA-9 Zest & $.602 *[.288, .807]$ & $<.001$ & $.727 *[.450, .891]$ & $<.001$ \\
\hline VIA-11 Kindness & $.491 *[.195, .738]$ & .004 & $.235[-.062, .529]$ & .196 \\
\hline VIA-23 Humour & $.466 *[.204, .677]$ & .007 &. $\mathbf{5 3 9} *[.223, .776]$ & .001 \\
\hline VIA-12 Social Intelligence & $.464 *[.206, .687]$ & .008 & $.476 *[.105, .741]$ & .006 \\
\hline VIA-13 Teamwork & $.458 *[.200, .649]$ & .008 &. $\mathbf{5 0 3} *[.249, .719]$ & .003 \\
\hline VIA-16 Forgiveness & $.389[.072, .649]$ & .028 & $.429 *[.133, .661]$ & .014 \\
\hline VIA-21 Gratitude & $.367[-.061, .761]$ & .039 & $.356 *[.008, .637]$ & .045 \\
\hline VIA-20 Appreciation of beauty & $.365[-.040, .689]$ & .040 & $.087[-.207, .344]$ & .636 \\
\hline VIA-6 Bravery & $.363[-.022, .600]$ & .041 & $.536 *[.118, .778]$ & .002 \\
\hline VIA-15 Leadership & $.343[.039, .598]$ & .055 & $.406[.044, .653]$ & .021 \\
\hline VIA-14 Fairness & $.337[-.029, .598]$ & .059 & $.300[-.005, .560]$ & .095 \\
\hline VIA-7 Persistence & $.336[-.062, .672]$ & .060 & $.644 *[.390, .814]$ & $<.001$ \\
\hline VIA-24 Spirituality & $.330[-.030, .637]$ & .066 & $.436 *[.122, .683]$ & .013 \\
\hline VIA-2 Curiosity & $.269[-.124, .588]$ & .137 & $.634 *[.353, .791]$ & $<.001$ \\
\hline VIA-19 Self-regulation & $.224[-.246, .626]$ & .217 & $.340[-.056, .620]$ & .057 \\
\hline VIA-10 Love & $.207[-.152, .615]$ & .257 & $.519 *[.118, .794]$ & .002 \\
\hline VIA-1 Creativity & $.199[-.077, .472]$ & .275 & $.319[-.074, .608]$ & .075 \\
\hline VIA-5 Perspective & $.188[-.205, .509]$ & .303 & $.576 *[.310, .761]$ & .001 \\
\hline VIA-18 Prudence & $.175[-.230, .502]$ & .339 & $.133[-.351, .549]$ & .467 \\
\hline VIA-17 Modesty & $.158[-.240, .446]$ & .387 & $-.031[-.405, .362]$ & .867 \\
\hline VIA-8 Authenticity & $.142[-.243, .521]$ & .437 & $.300[-.109, .619]$ & .095 \\
\hline VIA-4 Love of learning & $.125[-.270, .456]$ & .494 & $.338[-.146, .681]$ & .059 \\
\hline VIA-3 Open-mindedness & $-.149[-.479, .190]$ & .415 & $.130[-.335, .475]$ & .478 \\
\hline
\end{tabular}

$\mathrm{N}=32$ in both groups.

Benjamini and Hochberg (1995) corrected significance level $q<.02$

Bolded values with * indicate statistical significance

95\% Confidence Intervals are reported in [ ] 